\title{
O tabuleiro da Educação Básica: o novo Fundeb e a Escola Pública
}

\author{
Thais Conte Vargas ${ }^{1}$ \\ José Luís Bizelli² \\ José Anderson Santos Cruz3
}

\begin{abstract}
RESUMO
Diante da falta de um Sistema Educacional Único, para o Brasil, o que daria visibilidade à estrutura organizacional e aos dados de desempenho, o trabalho analisa indícios de um aumento de participação do setor privado na oferta de Educação Básica. O caminho escolhido foi acompanhar a flexibilização da legislação naquilo que diz respeito às possibilidades de o investimento público ser utilizado por empresas privadas de educação. Mascarados por um discurso de desqualificação da escola pública enquanto local onde se ensina o aluno para os desafios do futuro, desafios tecnológicos de um mundo digital, e pela construção de indicadores de avaliação que pouco contribuem para aferir a relação ensino-aprendizagem, o jogo de privatização da Escola Básica está sendo jogado no presente momento.
\end{abstract}

PALAVRAS-CHAVE: Educação básica. Escola pública. Empresas educacionais. Política pública. Investimento público.

The board game of Basic Education: new Fundeb and the Public School

\begin{abstract}
Given the lack of a Single Educational System in Brazil, which would give visibility to the organizational structure and performance data,
\end{abstract}

1 Doutoranda em Educação Escolar. Universidade Estadual Paulista, Araraquara, SP, Brasil. Orcid: https://orcid.org/0000-0001-8127-5257.E-mail: thaiscontev@ hotmail.com.

${ }^{2}$ Livre docente. Universidade Estadual Paulista, Araraquara, SP, Brasil. Orcid: http://orcid.org/0000-0002-66341444.E-mail: jose.bizelli@unesp.br.

${ }^{3}$ Doutor Educação Escolar. Universidade Estadual Paulista, Araraquara, SP, Brasil. Orcid: https://orcid.org/00000001-5223-8078. E-mail: anderson.cruz@unesp.br. 
the paper analyzes signs of an increased participation of the private sector in the provision of Basic Education. The path chosen was to accompany the flexibilization of legislation regarding the possibilities of public investment to be used by private education companies. Masked by a discourse of disqualification of the public school as the place where the student is taught for the challenges of the future, technological challenges of a digital world, and by the construction of assessment indicators that contribute little to measuring the teaching-learning relationship, the game of privatization of the Basic School is being played at the current time.

KEYWORDS: Basic education. Public school. Educational companies. Public policy. Public investment.

\section{La Junta de Educación Básica: el nuevo Fundeb y la Escuela Pública}

\section{RESUMEN}

Ante la falta de un Sistema Educativo Único, para Brasil, que dé visibilidad a la estructura organizacional y los datos de desempeño, el trabajo analiza indicios de un incremento en la participación del sector privado en la provisión de Educación Básica. El camino elegido fue acompañar la flexibilidad de la legislación en lo que se refiere a las posibilidades de que la inversión pública sea utilizada por las empresas educativas privadas. Enmascarado por un discurso de descalificación de la escuela pública como lugar donde se instruye a los estudiantes para los desafíos del futuro, los desafíos tecnológicos de un mundo digital, y para la construcción de indicadores de evaluación que poco hacen para calibrar la relación enseñanza-aprendizaje, el juego de En la actualidad se está jugando la privatización de la Escuela Básica.

PALABRAS CLAVE: Educación básica. Escuela pública. Empresas educativas. Política pública. Inversión pública.

$$
* * *
$$




\section{Introdução}

A oferta brasileira de ensino básico concentra volumosa quantidade de recursos estatais que viabilizam uma extensa rede educacional. De acordo com o Censo Escolar de 2019, são 139.176 escolas públicas de educação básica em funcionamento no país, que se somam a 41.434 estabelecimentos privados. As instituições - públicas e privadas - têm matriculados 47.874.246 alunos e contratam 2.212.018 docentes. Os dados não são apenas grandiosos, mas desenham a complexidade de gestão da Educação brasileira que, além de ministrar o conjunto de conhecimentos e atividades considerados fundamentais para a formação intelectual, científica e cidadã das crianças e adolescentes, em cada período histórico determinado, ainda dispõe de um conjunto de serviços - saúde e prevenção; manutenção de equipamentos; fornecimento de alimentação; transporte escolar; e distribuição de livros didáticos - que viabilizam o funcionamento escolar.

A proporção dos investimentos públicos realizados no setor educacional como um todo, em relação ao Produto Interno Bruto (PIB) nacional, elevou-se de 4,6\% nos anos 2000 para $6,3 \%$ em $2017^{4}$, sendo que do total, 1,1\% do aumento concentrou-se na Educação Básica (EB), e 0,6\% no nível Superior (INEP/MEC, 2017). Considerando o tamanho das redes e a quantidade de alunos atendidos, a desproporção de recursos alocados para os dois setores - EB e Superior - é alarmante.

Importa mencionar que, quando se toma os números do percentual do PIB aplicado, passam a estar incluídos despesas outras como recursos para bolsa de estudo, financiamento estudantil e a modalidade de aplicação Transferências Correntes e de Capital ao Setor Privado. Fica evidente que, dado o volume elevado de recursos públicos investidos no setor educacional, passa a haver fortes interesses de Mercado em disputar uma fatia do financiamento público. O argumento deste artigo é que, no período recente,

\footnotetext{
${ }^{4}$ Dados oficiais mais recentes, publicados e disponíveis.
} 
tem aumentado o interesse privado sobre os recursos públicos destinados à Educação, particularmente, sobre aqueles destinados à EB.

\section{Aspectos relevantes da história recente}

As relações que o Setor Privado estabelece com as administrações governativas na área educacional têm sido objeto de pesquisas acadêmicas que abordam o tema sob diversos aspectos: as origens da associação público-privada (PAIVA, 2016); as implicações para o fortalecimento das políticas estatais (FALABELLA; PIRES; PERONI, 2019); a concreta qualidade da oferta (SILVA, 2016); as distorções pela monopolização crescente do setor privado (PEREIRA, 2017).

Para iniciar um diálogo sobre a questão, é essencial entender como a legislação educacional normatiza investimentos repassados ao Setor Privado. A Lei no 11.494 de 2007 (BRASIL, 2007), que institucionaliza o FUNDEB, Fundo de Manutenção e Desenvolvimento da EB e de Valorização dos Profissionais da Educação, garante o repasse de verbas a instituições comunitárias, confessionais e filantrópicas, sem fins lucrativos e conveniadas ao poder público, que atendam a demanda por matrículas na pré-escola. Além disso, dispõe que ao menos 60\% dos recursos do Fundo sejam utilizados para o pagamento de salários docentes, enquanto os $40 \%$ restantes necessitam ser investidos em Manutenção e Desenvolvimento do Ensino, sem vetar o uso deste montante para práticas como aquisição de material didático fornecido por instituições privadas, abrindo espaço para que as mesmas ocorram. O novo FUNDEB (BRASIL, 2020), promulgado em agosto de 2020, atualiza para 70\% o percentual mínimo de recursos alocados para pagamentos dos profissionais da educação básica, mas continua não vetando a compra de material didático de sistemas privados ou o pagamento por vagas na educação infantil. 
O Plano Nacional de Educação - que possui como meta elevar o gasto com Educação para 10\% do PIB até o ano final de sua vigência, em 2024 também não veta explicitamente a transferência de recursos ao Mercado. Mais grave, porém, foi a aprovação, no Senado e na Câmara dos Deputados, da Emenda Constitucional n ${ }^{\circ}$. 95, conhecida como PEC do Teto (BRASIL, 2016). A Emenda, que passou a vigorar no exercício financeiro de 2017, altera o regime fiscal vigente no país ao propor um limite para os gastos públicos durante os próximos vinte anos.

De acordo com Rossi e Dweck (2016), a medida terá forte impacto na área educacional, que perderá proporcionalmente orçamento em função do crescimento da população. Assim, a educação pública, que já sofre com a insuficiência de recursos, terá ainda mais dificuldades para atender a todos os alunos que dela dependerão.

A situação fiscal do país, neste cenário marcado pela austeridade e pela redução do tamanho do Estado, amplia ainda mais o efeito da transferência de recursos para o Setor Privado, o que já vem ocorrendo de forma notável. Mesmo nas duas décadas anteriores, quando o Brasil viveu um período de prosperidade econômica aliada à expansão da Educação Superior e Profissionalizante, os caminhos escolhidos para a ampliação de vagas fortaleceram grupos educacionais privados.

Políticas públicas de benefícios como o PROUNI - que garantia a oferta de vagas em Instituições Privadas de Ensino Superior, por meio da redução de impostos cobrados da empresa - e o FIES - crédito educativo com taxas de juros menores que as praticadas pelo mercado - consolidaram o modelo de negócio de universidades particulares, que passaram a utilizálas como fonte de financiamento direto: de acordo com publicação especializada no setor de investimentos (InfoMoney), o FIES, em 2014, foi responsável por 49\% das receitas totais da Ser Educacional (SEER3), 44\% da Kroton (KROT3), 40\% da Estácio (ESTC3) e 38\% da Anima (ANIM3), os maiores conglomerados educacionais privados do país (UMPIERES, 2015). 
Durante esse período, tais empresas figuraram como as mais lucrativas na Bovespa, como explica Sguissardi:

De agosto de 2012 a agosto de 2014, por exemplo, enquanto o Ibovespa (índice do total de cerca de 350 empresas) teve uma redução de $3,67 \%$; a Vale (VALE5), redução de 13,48\%; e a Petrobras (PETR4), valorização de $9,32 \%$ de suas ações; a Kroton (KROT3) teve uma valorização de 314\% e a Estácio (ESTC3), 240,97\% de suas respectivas ações (SGUISSARDI, 2015, p. 870).

A partir de 2015, as normas para a concessão do FIES se tornaram mais rígidas, o que acarretou perda de valor de mercado para estas companhias. Desde então, tem-se observado uma mudança no perfil do investimento: antes atraídos pelo nível superior, atualmente os conglomerados educacionais buscam uma aproximação das instituições de ensino básico.

Corrobora a situação descrita, a compra do grupo Somos Educação pela Kroton, no início de 2018. Dona da rede de colégios Anglo; das editoras Saraiva, Ática e Scipione; e da escola de idiomas Red Balloon, a marca é responsável pelas matrículas, em escolas básicas e cursos de línguas, de 62 mil alunos ${ }^{5}$. Com a aquisição, a Kroton ampliou sua participação no mercado de educação básica, ainda pouco explorado: enquanto $73,7 \%$ dos discentes do Ensino Superior frequentam instituições privadas - o que demonstra claro limite de mercado para crescimento da oferta no segmento - apenas $25,3 \%$ das matrículas de creche e pré-escola, 18\% de ensino fundamental e 12,6\% de ensino médio estavam em colégios particulares, no ano de 2019 , de acordo com a PNAD Contínua divulgada pelo IBGE (2019).

A presença de grupos educacionais privados na $\mathrm{EB}$, ainda que esteja se ampliando nos últimos anos, não é recente. Buscando se beneficiar de concessões como repasses, bolsas, isenções fiscais, perdão de dívidas, convênios e parcerias, instituições particulares procuraram manter relação estreita com prefeituras e governos estaduais.

\footnotetext{
${ }^{5}$ A atuação da Kroton na educação brasileira foi inclusive tema de pesquisa de mestrado (GALZERANO, 2016).
} 
No caso de prefeituras, com a municipalização do Ensino Fundamental (EF), tal participação foi mais intensa ${ }^{6}$. Equipes locais recorreram a empresas privadas de educação na busca por assessoria de gestão, já que, na maioria dos casos, a municipalização ocorreu sem que os gestores estivessem preparados para assumir a responsabilidade legal exigida. A compra de materiais didáticos ${ }^{7}$ e o repasse direto de recursos a instituições privadas que ofertam vagas na Educação Infantil - etapa de ensino na qual poderes locais não conseguem atender a demanda passam a ser práticas comuns.

A mídia amplia diariamente o discurso de que a escola pública está "ultrapassada", já que conhecimentos transmitidos no espaço escolar não condizem com a realidade contemporânea; fortalece o argumento favorável aos sistemas privados de ensino: alternativa "antenada" com as tendências do mundo digital, alternativa que prepara alunos para o mundo tecnológico embarcado em metodologias de ensino que são utilizadas no cotidiano das escolas particulares. A pandemia causada pelo vírus Covid-19 ampliou essa percepção: certamente há dúvidas acerca da capacidade de escolas públicas oferecerem ambientes adequadamente higienizados aos discentes que a frequentam.

A questão do material didático é um exemplo. Por meio do Programa Nacional do Livro Didático, o governo federal disponibiliza às escolas material didático adquirido, muitas vezes, das mesmas editoras que publicam os livros vendidos pelos sistemas de ensino particulares. Ao recusar a participação no PNLD e aderir à compra de material pago, as escolas públicas colaboram, portanto, para a dupla transferência de recursos ao setor privado, além de utilizarem, por fim, livros similares.

O Sistema SESI pode ser tomado como caso emblemático. Financiado com recursos públicos - 1,5\% incidente sobre o total da remuneração paga pelas empresas do setor industrial - e com a finalidade de proporcionar

\footnotetext{
${ }^{6} \mathrm{O}$ tema foi aprofundado em Vargas (2019).

${ }^{7}$ Frequentemente acompanhados de cursos para docentes e outros serviços, vendidos por empresas como um pacote fechado denominado "sistemas de ensino", com o intuito de elevar o custo total do investimento.
} 
serviços sociais - dentre eles, educação básica - aos funcionários da indústria, a instituição, atualmente, lucra com a venda de materiais didáticos e sistemas de ensino para redes municipais. Compõem-se um ambiente propício para que diversos mecanismos legais permitam que o setor privado seja o destinatário final de investimentos públicos no campo da educação.

No início dos anos 2000, um grupo de empresários interessados na temática educacional fundou o movimento "Todos pela Educação". A bandeira que os agrega até hoje é a defesa de uma "educação para o século XXI” que só será possível - segundo o movimento - se houver a responsabilização da equipe escolar pelos resultados obtidos por alunos em avaliações de larga escala. Fica evidente um modelo de parceria públicoprivada, que admite a transferência de recursos para o mercado e, ao mesmo tempo, imputa ao setor público o ônus do fracasso da política.

Está descrito o cenário atual onde se move a escola pública: poucos investimentos diretos e inúmeras exigências de desempenho. Agravante: alta taxa de distorção idade-série - em 2019, 16,2\% dos alunos matriculados no EF possuíam idade superior à recomendada para a respectiva série, problema que atingia também $26,2 \%$ dos discentes cursando o Ensino Médio, segundo o Censo da Educação Básica (INEP, 2019). Agravante: tentativa de ampliar a Educação a Distância ${ }^{8}$, inclusive para o EF.

Há um movimento, portanto, para enfraquecer a educação oferecida de forma pública e gratuita, identificando-a como ambiente inadequado para: ensino e aprendizagem de diferentes literacias e linguagens científicas; construção de conhecimentos significativos; aquisição do uso de ferramentas tecnológicas digitais; socialização de valores cidadãos; vivência da pluralidade na diversidade e do respeito ao ambiente natural; enfim, formação de seres humanos melhores.

\footnotetext{
${ }^{8}$ Modalidade que vem crescendo, sobretudo nas instituições privadas, e que mostrou sua força durante a pandemia de 2020 .
} 
O movimento descrito caracteriza lance estratégico no tabuleiro de direcionar recursos públicos para fortalecer empresas privadas que oferecem Educação.

\section{Propostas legislativas e movimentos do Mercado}

Nos últimos anos, o Brasil passou por transformações políticas e econômicas: após um período de estabilidade macroeconômica e crescimento acima da média mundial, com amplos impactos sociais e inclusão de parcela considerável da população da chamada classe média, o país padece agora de grave crise financeira - agravada pela pandemia de Covid-19 -, com aumento acentuado do desemprego e diminuição da arrecadação, o que coloca em risco o financiamento de políticas sociais, especialmente aquelas voltadas à Educação.

Como já mencionado, em tentativa de reduzir gastos públicos, aprovou-se Emenda Constitucional que impede a ampliação de investimentos federais em áreas como Educação e Saúde por vinte anos. Na prática, são menos recursos públicos para ambas as áreas: abre-se, assim, espaço para o avanço do setor privado na oferta de serviços sociais, justificado por um discurso de maior eficiência empresarial, frente aos "baixos" resultados oferecidos por organizações de protagonismo estatal.

Enquanto as universidades brasileiras passaram de 2.314 instituições - 2.069 privadas e 245 públicas -, em 2009, para 2.448 - 2.152 particulares e 296 públicas -, em 2017, as escolas de Ensino Básico caíram de 191.466 estabelecimentos, em 2007, para 181.616, em 2014. Ao contrário da Educação Superior, que teve apenas 83 instituições privadas a mais no período mencionado, as escolas particulares de ensino infantil, fundamental e médio saltaram de 28.647, em 2007, para 34.898, em 2014, ao passo que as públicas diminuíram de 163.074, em 2007, para 147.123, em 2014 (InepData). Analisando: o Ensino Superior, no período, teve um crescimento que atingiu as instituições públicas e particulares; o Ensino Básico, além de 
ter diminuído o número de escolas, assistiu crescimento da oferta privada sobre a pública, movimento ampliado pela prestação de serviço direto oferecido por empresas educacionais.

Entre a jurisprudência que cristaliza a tendência descrita, pode-se citar a Proposta de Emenda Constitucional n ${ }^{\circ}$. 03/2019, defendida na Comissão Especial destinada a discutir a continuidade do FUNDEB como fundo permanente, que sugere alterar o artigo 3 da PEC 15/2015 e o artigo 213 da Constituição Federal, para possibilitar que estados e municípios optem por direcionar parte de recursos do FUNDEB para organizações da sociedade civil e para financiar bolsas de estudo em instituições de ensino privadas.

De acordo com a justificativa da PEC:

É preciso direcionar o foco do FUNDEB para a razão central da política educacional, que é o aluno educado e não a estrutura escolar estatal. É dado que é responsabilidade do Estado garantir ensino público às crianças e jovens brasileiros. No entanto, é preciso destacar que a escola em si é apenas um meio para que atingir fins educacionais. A finalidade do processo educacional é o aprendizado do aluno; logo é ele que deve ser financiado, não a escola. Por isso, faz-se urgente a possibilidade de permitir o acesso de todos à escolarização de melhor qualidade independente se ela se encontra no setor público ou privado. Permitir que crianças de famílias em situação de vulnerabilidade social também tenham acesso a um ensino de qualidade enquanto se busca soluções para elevar o desempenho das escolas públicas é também uma questão de justiça social. É por isso que é importante explorar inovações no modelo de ensino no Brasil, como oferecer bolsas em instituições de ensino privadas para alunos da rede pública e permitir a expansão das escolas conveniadas (chamadas de "charter schools"). A vantagem destas escolas é que elas trazem os benefícios da gestão privada para as escolas públicas. Dentro desse modelo, governos podem celebrar contratos com organizações sociais sem fins lucrativos que possam atuar na área de educação em prol da sociedade. Para tal, a proposta visa possibilitar que estados e municípios utilizem recursos do FUNDEB para financiar bolsas similares ao ProUni para o ensino básico assim como financiar escolas organizadas sob o marco legal das organizações da sociedade civil. É importante lembrar que, aprovando esta proposição, não se estará abandonando o ensino público. Pelo contrário. Com 
avaliações e testes de outros modelos de gestão, haverá ferramentas para aprimorar as redes públicas, dando assim um importante passo para se construir um sistema que tenha o alcance da educação pública com a qualidade da gestão privada. (BRASIL, 2019a, p. 2, grifos nossos)

Proposta por deputados do partido Novo - autointitulado liberal - e do Cidadania -que se diz empenhado na fundação de um novo socialismo -, a PEC considera que os recursos públicos devem ser direcionados, para as redes que apresentem "melhores resultados", consignando no texto a intenção de estimular "a gestão privada para as escolas públicas”. Dois outros Projetos de Lei que tramitam no Congresso, hoje, propõem a instituição do "voucher-creche" e do "voucher-Educação", auxílios concedidos a funcionários de empresas privadas para cobrir despesas efetuadas com a educação básica dos filhos.

O Mercado privado da EB está em franca movimentação, a partir de 2017. Já foi mencionada a notável incorporação da Somos Educação pela holding Saber, subsidiária da Kroton que atua na EB. O grupo Estácio, segundo maior conglomerado privado atuante no Ensino Superior, também iniciou sua atuação na EB, oferecendo turmas de Ensino Médio em seus próprios campi. Novos players se apresentam, como o Eleva Educação, holding do fundo de investimento Gera Venture Capital, que tem como principal investidor Jorge Paulo Lemann: a empresa, em pouco mais de um ano de atuação, conquistou 70 mil alunos em escolas parceiras da rede.

Descreve-se, assim, um segundo lance estratégico naquele tabuleiro de direcionar recursos públicos para fortalecer empresas privadas que oferecem Educação.

\section{Indicadores e indicativos para o Novo FUNDEB:}

Está explícita a intenção do legislador para estabelecer a organização de um Sistema Nacional de Educação: a Lei que determina 
as diretrizes e bases da educação nacional, promulgada em 1996 (LDB, 1996), estabelece em seu artigo oitavo:

\section{TÍTULO IV}

Da Organização da Educação Nacional

Art. $8^{\circ}$ A União, os Estados, o Distrito Federal e os Municípios organizarão, em regime de colaboração, os respectivos sistemas de ensino (BRASIL, 1996, grifos nossos).

Passados 24 anos, o Brasil ainda não conseguiu construir seu Sistema. Evidência maior da ausência é que o tema, praticamente com a mesma redação, retorna na Emenda Constitucional promulgada em agosto de 2020, quando se dispõe sobre o novo - e agora permanente - FUNBED:

Art. $211[\ldots]$

$\S 4^{\circ} \mathrm{Na}$ organização de seus sistemas de ensino, a União, os Estados, o Distrito Federal e os Municípios definirão formas de colaboração, de forma a assegurar a universalização, a qualidade e a equidade do ensino obrigatório (BRASIL, 2020, grifos nossos).

A EC 108/20 também dispõe que parte dos recursos alocados às redes educacionais via FUNDEB deverão ser destinados àquelas que melhorarem seus índices:

Art. 212-A. Os Estados, o Distrito Federal e os Municípios destinarão parte dos recursos a que se refere o caput do art. 212 desta Constituição à manutenção e ao desenvolvimento do ensino na educação básica e à remuneração condigna de seus profissionais, respeitadas as seguintes disposições: [...] $\mathrm{V}$ - a complementação da União será equivalente a, no mínimo, $23 \%$ (vinte e três por cento) do total de recursos a que se refere o inciso II do caput deste artigo, distribuída da seguinte forma: [...]

c) 2,5 (dois inteiros e cinco décimos) pontos percentuais nas redes públicas que, cumpridas condicionalidades de melhoria de gestão previstas em lei, alcançarem evolução de indicadores a serem definidos, de atendimento e melhoria da aprendizagem com redução das desigualdades, nos termos do sistema nacional de avaliação da educação básica" (BRASIL, 2020, grifos nossos). 
Cabe, portanto, perguntar: quais são os "indicadores a serem definidos"? Atualmente, o índice que mede a qualidade da EB nacional é o IDEB - Índice de Desenvolvimento da Educação Básica, elaborado, em 2007, pelo INEP - Instituto Nacional de Estudos e Pesquisas Educacionais Anísio Teixeira. O índice reflete os resultados alcançados pelos discentes na avaliação da Prova Brasil - aplicada a alunos matriculados no quinto ano do $\mathrm{EF}$, buscando avaliar competências de língua portuguesa e matemática.

O IDEB é utilizado para o acompanhamento das metas de qualidade do Plano de Desenvolvimento da Educação (PDE) para a EB. O desafio nacional é chegar, em 2022, com IDEB igual a 6,0 - média que corresponde a um sistema educacional de qualidade comparável ao de países desenvolvidos. O período estipulado tem como base a simbologia do bicentenário da Independência, proclamada em 1822. Cada sistema educacional deve evoluir segundo pontos de partida distintos, o que exige esforço maior daqueles que partem de pior situação. O intuito é a redução da desigualdade educacional.

Outro fator conjuntural que deve ser destacado diz respeito ao ambiente de crítica generalizada às ações estatais, construído por correntes neoliberais, muito ativas na década de 1990. Organismos internacionais - financeiros e consultivos - recomendavam aos países considerados 'em desenvolvimento' a redefinição das funções entregues ao setor público e ajuste fiscal que equilibrasse as contas nacionais. A necessidade de 'enxugar' o tamanho do Estado, reduzindo-o a uma estrutura que cumprisse apenas tarefas consideradas essenciais, deu força à ideia pragmática de que a eficiência da gestão pública deveria ser constantemente medida, preferencialmente, através de avaliações externas sem a participação de gestores locais. Assim, indicadores passam a ser instrumentos indispensáveis para a formulação e avaliação de políticas, incluindo as educacionais. 
Cabe, portanto, a questão: como o IDEB, atual indicador de qualidade, vem sendo utilizado na formulação de políticas? Para Assunção e Carneiro (2012, p. 15, grifo nosso), não de forma satisfatória:

O IDEB, como essência do PDE, revela as contradições de um modelo de avaliação que pode ser interessante do ponto de vista de um mecanismo de verificação de rendimento, entretanto, é utilizado como um mecanismo de regulação que atende também aos interesses de empresas privadas que têm direta interferência na política educacional brasileira. Assim, qualidade na educação passa a ser comparada com crescimento nas pontuações, gerando situações ilusórias, haja vista que responder a testes de múltipla escolha significa apenas o ato de escolher uma resposta, sem necessariamente haver qualquer reflexão sobre a mesma, o que é de suma importância no processo de construção do conhecimento. Utilizar este tipo de instrumento na educação serve tão somente para classificar e definir posições, favorecendo a segregação e a desintegração e, evidentemente, acarretando desgaste e sofrimento. Além disto, uma das graves consequências é o aumento da pressão sobre o trabalho docente, dada a avalanche de prêmios e castigos, o que é mais uma ilusão, uma vez que essa lógica não tem efeito duradouro.

Vários autores apontam a dificuldade governamental em utilizar-se de ferramentas avaliativas para a elaboração de estratégias que possam auxiliar e promover a melhoria da qualidade do ensino. Horta Neto, em tese defendida em 2013, considera que nos estados de Minas Gerais e São Paulo:

[...] os testes avaliativos tiveram influência marginal sobre as políticas educacionais voltadas para o ensino fundamental, pois se tornaram um fim em si mesmo e não elementos centrais para a formulação de políticas educacionais. Outrossim, os resultados dos testes são usados pelo Estado como instrumento de regulação do trabalho realizado pela escola e seus profissionais (HORTA NETO, 2013, p. 29).

É possível acrescentar que - para além da escolha e do uso de um indicador - é praticamente consenso na literatura especializada em avaliação da educacional que vincular o resultado de testes padronizados ao financiamento que a escola recebe - ou deixa de receber - não é benéfico 
pedagogicamente. Após promulgar a Lei No Child Left Behind - nenhuma criança deixada para trás -, em 2002, os Estados Unidos experimentaram o chamado teach to the test - ensinar para a prova. Ao condicionar recursos federais a redes que atingissem resultados em testes padronizados, observou-se como consequência que professores passaram a dedicar tempo de sala de aula para ensinar: como preencher corretamente as folhas de provas - lidas mecanicamente -; o que fazer quando o tempo de avaliação se aproxima do final; quando chutar ou não uma questão (PHELPS, 2011). Ademais, a própria autonomia docente é questionada:

Item teachers narrow their instruction, organizing their teaching around clones of the particular questions most likely to be found on the test-and thus teach only the bits of knowledge students are most likely to encounter on exams. For example, item teachers might drill students on a small set of vocabulary words expected to be assessed rather than employing instructional strategies that help students develop the kind of rich and broad vocabulary that best contributes to strong reading comprehension (JERALD, 2006, p. 2). ${ }^{9}$

O problema é maior em contextos nos quais a educação básica é confrontada com desafios estruturais: desigualdades sociais e educacionais históricas. Sodel (2015) - em trabalho sobre a implantação de reformas neoliberais na educação do estado da Louisiana, que possui um dos menores IDHs dos Estados Unidos - considera que:

Os professores restringem sua instrução, organizando seus ensinamentos em torno de clones de perguntas mais prováveis de serem encontradas no teste - e, assim, ensinam apenas pedaços de conhecimento que os alunos têm maior probabilidade de encontrar em exames. Por exemplo, professores podem treinar os alunos em um pequeno conjunto de palavras que devem ser avaliadas em vez de empregar estratégias de ensino que os ajudam a desenvolver o tipo de rico e amplo vocabulário

\footnotetext{
${ }^{9}$ Item teachers narrow their instruction, organizing their teaching around clones of the particular questions most likely to be found on the test - and thus teach only the bits of knowledge students are most likely to encounter on exams. For example, item teachers might drill students on a small set of vocabulary words expected to be assessed rather than employing instructional strategies that help students develop the kind of rich and broad vocabulary that best contributes to strong reading comprehension (JERALD, 2006, p. 2).
} 
que melhor contribui para uma forte compreensão de leitura (SONDEL, 2015, p. 1, tradução nossa). ${ }^{10}$

Tais experiências reforçam a ideia de que indicativos internacionais e nacionais questionam a validade de indicadores para avaliar sucesso educacional, aconselhando cautela na adoção de modelos similares de organização escolar. $O$ açodamento para assumir os indicadores como indicativos, no Brasil, passa a constituir-se como mais um lance estratégico no tabuleiro para afirmar o valor do mercado educativo frente à fragilidade das escolas públicas.

\section{Considerações finais}

Ao analisar a situação educacional brasileira, a primeira constatação é a falta de um Sistema Único de Educação - à semelhança do Sistema Único de Saúde - que pudesse dar transparência no atendimento educativo completo oferecido à população. Dados fundamentais se perdem particularmente, os que dizem respeito aos serviços públicos, privados e oferecidos pelo terceiro setor - em múltiplos documentos setoriais.

Uma segunda constatação - mainstream da análise contida neste artigo - é que, em período recente, o financiamento público da Educação brasileira vem se tornando mais disponível aos conglomerados privados, provocando um redirecionamento de interesses empresariais, dirigidos para uma diversificação na segmentação do mercado: depois de anos apostando em instituições de ensino superior, os capitais privados voltam-se agora para investimentos na EB.

O trabalho analisou três lances estratégicos no tabuleiro colocado: 1 . em uma disputa por resultado entre escolas públicas e privadas, as últimas se colocam como ambiente propício a habilitar estudantes a enfrentar o mundo atual, tecnológico e conectado; 2. as normas e procedimentos vêm

\footnotetext{
${ }^{10}$ Teachers' lack of capacity and freedom to develop participatory and justice-oriented citizens stands in stark contrast to the justice-based rhetoric employed by market-based reformers and further calls into question the assumption that increased test scores are an indication of successful reforms (SONDEL, 2015, p. 1).
} 
abrindo brechas para que o investimento público possa ser direcionado às escolas privadas, não só em linhas diretas, mas em serviços e bolsas que minimizem os riscos da inadimplência, ou seja, os riscos do investimento capitalista de mercado; 3. apesar de indicativos que demonstram falhas nos indicadores para avaliar relações de ensino-aprendizagem, cria-se uma imagem pública de que indicadores educacionais corroboram a superioridade do setor privado contra a escola pública, já que fortemente favoráveis aos resultados salutares do mercado competitivo na Educação.

Xeque-mate! Por tudo que foi apresentado até aqui, é possível perceber que, dado o ambiente de desqualificação da escola pública, as facilidades de o público financiar a escola privada e a redução de recursos, especificamente, para a Educação Básica, nos próximos anos, ver-se-á uma invasão bárbara de conglomerados privados a disputar este mercado consumidor.

\section{Referências}

ASSUNÇÃO, M. P.; CARNEIRO, V. L. O papel do estado e as políticas públicas de educação: uma análise das avaliações externas no ensino fundamental. RBPAE: Revista Brasileira de Política e Administração da Educação, Porto Alegre, v. 28, n. 3, p. 645-663, set/dez. 2012.

BRASIL. Câmara dos Deputados. Comissão Especial. Proposta de Emenda Constitucional n. 3 de 2019. Altera o art. 3 da PEC 15/2015 e o art. 213 da Constituição Federal para possibilitar que estados e municípios optem por direcionar parte dos recursos do FUNDEB para organizações da sociedade civil e para financiar bolsas de estudo em instituições de ensino privadas. Brasília, DF: Câmara dos Deputados, 2019. Disponível em:

https://www.camara.leg.br/proposicoesWeb/prop_mostrarintegra?codteor= 1760837\&filename=EMC+3/2019+PEC01515+\%3D \%3E+PEC+15/2015. Acesso em 10 jun. 2020.

BRASIL. Câmara dos Deputados. Projeto de Lei n. 1648 de 2019. Institui o Programa de Voucher-Creche e altera a Lei n. 10.893, de 13 de julho de 2004. Brasília, DF: Câmara dos Deputados, 2019. Disponível em: https://www.camara.leg.br/proposicoesWeb/prop_mostrarintegra?codteor=17 21743\&filename=Tramitacao-PL+1648/2019. Acesso em 10 jun. 2020. 
BRASIL. Câmara Dos Deputados. Projeto de Lei n. 1649 de 2019. Institui o Voucher-Educação e altera a Lei n. 10.893, de 13 de julho de 2004. Brasília, DF: Câmara dos Deputados, 2019. Disponível em: https://www.camara.leg.br/proposicoesWeb/prop mostrarintegra?codteor= 1721747\&filename=Tramitacao-PL+1649/2019. Acesso em 10 jun. 2020.

BRASIL. Emenda constitucional n. 95, de 15 de dezembro de 2016. Altera o Ato das Disposições ConstitucionaisTransitórias, para instituir o Novo RegimeFiscal, e dá outras providências. Diário Oficial da União: Seção 1, Brasília, DF, p. 2, col. 2, 16 dez. 2016.

BRASIL. Lei n. 11.494, de 20 de junho de 2007. Lei do Fundo de Manutenção e Desenvolvimento da Educação Básica e de Valorização dos Profissionais da Educação. Diário Oficial da União: Seção 1, Brasília, DF, p. 7, 21 jun. 2007.

BRASIL. Lei n. 9.394, de 20 de dezembro de 1996. Estabelece as diretrizes e bases da educação nacional. Diário Oficial da União: Seção 1, Brasília, DF, p. 27833,23 dez. 1996.

BRASIL. Presidência da República. Casa Civil. Subchefia para Assuntos Jurídicos. Emenda Constitucional n. 108, de 26 de agosto de 2020. Altera a Constituição Federal para estabelecer critérios de distribuição da cota municipal do Imposto sobre Operações Relativas à Circulação de Mercadorias e sobre Prestações de Serviços de Transporte Interestadual e Intermunicipal e de Comunicação (ICMS), para disciplinar a disponibilização de dados contábeis pelos entes federados, para tratar do planejamento na ordem social e para dispor sobre o Fundo de Manutenção e Desenvolvimento da Educação Básica e de Valorização dos Profissionais da Educação (Fundeb); altera o Ato das Disposições Constitucionais Transitórias; e dá outras providências. Diário Oficial da União: Seção 1, Brasília, DF, p. 5, 27 ago. 2020.

FALABELLA, A.; PIRES, D O.; PERONI, V. M. V. As formas de privatização no Brasil e no Chile e as implicações para a democratização da Educação Pública. Revista IberoAmericana de Estudos em Educação, Araraquara, v. 14, n. esp. 3, p. 1813-1828, out., 2019. E-ISSN: 1982-5587. DOI: https://doi.org/10.21723/riaee.v14iesp.3.12765.

GALZERANO, L. S. Grupos empresariais e educação básica: estudo sobre a Somos Educação. 2016. 167 f. Dissertação (Mestrado em Educação) Universidade Estadual de Campinas, Campinas, 2016.

HORTA NETO, J. L. As avaliações externas e seus efeitos sobre as políticas educacionais: uma análise comparada entre a União e os Estados de Minas Gerais e São Paulo. 2013. 358 f. Tese (Doutorado em Política Social) Universidade de Brasília, Brasília, 2013. Disponível em:

https://repositorio.unb.br/handle/10482/14398. Acesso em: 6 abr. 2020. 
IBGE. Diretoria de Pesquisas, Coordenação de Trabalho e Rendimento. Pesquisa Nacional por Amostra de Domicílios Contínua 2016/2019. Rio de Janeiro, 2020. Disponível em:

https://biblioteca.ibge.gov.br/visualizacao/livros/liv101736 informativo.pdf. Acesso em 16 set. 2020

INEP. Instituto Nacional de Estudos e Pesquisas Educacionais Anísio Teixeira. Censo da Educação Básica 2019. Brasília, Inep, 31 jan. 2020. Disponível em: http://inep.gov.br/sinopses-estatisticas-da-educacao-basica. Acesso em 16 set. 2020.

JERALD, C. D. 'Teach to the Test'? Just Say No. Washington, DC: The Center for Comprehensive School Reform and Improvement, 2006. Disponível em: http://www.csrclearinghouse.org/files/CenterIssueBriefJuly06.pdf. Acesso em: 6 abr. 2020.

PAIVA, R. T. O público não estatal na educação brasileira: uma política para a expansão da iniciativa privada. 2016. $195 \mathrm{f}$. Tese (Doutorado em Educação) - Universidade Estadual de Maringá, Maringá, 2016.

PEREIRA, T. L. Monopolização do Ensino Superior Privado no Brasil por meio de processos de fusões e aquisições: o grupo Uniesp em questão. 2017. 225 f. Tese (Doutorado em Educação) - Universidade Federal de Mato Grosso do Sul, Campo Grande, 2017.

PHELPS, R. P. Teach to the Test? The Wilson Quarterly (1976-), v. 35, n. 4, p. 38-42, 2011. DOI: $10.2307 / 41484371$

ROSSI, P.; DWECK, E. Impactos do novo regime fiscal na saúde e educação. Cadernos de Saúde Pública, Rio de Janeiro, v. 32, n. 12, 2016. Disponível em: https://www.scielosp.org/scielo.php?pid=S0102-

311X2016001400501\&script $=$ sci_arttext\&tlng=en\#. Acesso em 01 maio 2020. DOI: https://doi.org/10.1590/0102-311x00194316.

SGUISSARDI, V. Educação Superior no Brasil. Democratização ou massificação mercantil? Educ. Soc., Campinas, v. 36, n. 133, p. 867-889, dez. 2015. Disponível em:

http://www.scielo.br/scielo.php?script=sci_arttext\&pid=S010173302015000400867\&lng=pt\&nrm=iso. Acesso em: 6 abr. 2020.

SILVA, N. A. Educação Infantil e as relações público-privadas no município de Campinas: o Programa Naves-Mãe. 2016. 223 f. Dissertação (Mestrado em Educação) - Universidade Estadual de Campinas, Campinas, 2016. 
SONDEL, B. Raising citizens or raising test scores? teach for america, "no excuses" charters, and the development of the neoliberal citizen. Theory \& Research in Social Education, v. 43, n. 3, p. 289-313, 2015. DOI: https://doi.org/10.1080/00933104.2015.1064505.

UMPIERES, R. Entenda por que o melhor setor da Bolsa em 2014 já caiu mais de 40\% em 2015. InfoMoney, 13 jan. 2015. Disponível em:

https://www.infomoney.com.br/mercados/acoes-eindices/noticia/3803845/entenda-por-que-melhor-setor-bolsa-2014-caiu-mais2015. Acesso em: 6 abr. 2020.

VARGAS, T. C. Municipalização da educação: particularidades da gestão local em Araraquara - SP. 2019. Dissertação (Mestrado em Educação Escolar) - Universidade Estadual Paulista, Araraquara, 2019. 